\title{
BMJ Global Health Effect of removing the barrier of transportation costs on surgical utilisation in Guinea, Madagascar and the Republic of Congo
}

\author{
Mark G Shrime, ${ }^{1,2}$ Mirjam Hamer, ${ }^{3,4}$ Swagoto Mukhopadhyay, ${ }^{1}$ Lauren M Kunz, ${ }^{5}$ \\ Nathan H Claus, ${ }^{4}$ Kirsten Randall, ${ }^{4}$ Joannita H Jean-Baptiste, ${ }^{6}$ \\ Pierre H Maevatombo, ${ }^{7}$ Melissa P S Toh, ${ }^{4,8}$ Jasmin R Biddell, ${ }^{4}$ Ria Bos, ${ }^{4}$ \\ Michelle White ${ }^{4,9}$
}

To cite: Shrime MG, Hamer M, Mukhopadhyay S, et al. Effect of removing the barrier of transportation costs on surgical utilisation in Guinea, Madagascar and the Republic of Congo. BMJ Glob Health 2017;2:e000434. doi:10.1136/ bmjgh-2017-000434

Handling editor Seye Abimbola

Received 2 June 2017

Revised 25 August 2017

Accepted 31 August 2017

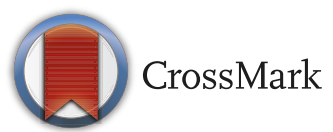

${ }^{1}$ Program in Global Surgery and Social Change, Harvard Medical School, Boston, Massachusetts, USA

2Department of Otolaryngology, Massachusetts Eye and Ear Infirmary, Boston, USA

${ }^{3}$ Paediatric Intensive Care Unit, University Medical Center, Utrecht, The Netherlands

${ }^{4}$ Mercy Ships, Lindale, USA

${ }^{5}$ National Institutes of Health, Bethesda, USA

${ }^{6}$ Freedom from Fistula

Foundation, Toamasina,

Madagascar

${ }^{7}$ WISE, Project on Reproductive Health, Toamasina, Madagascar ${ }^{8}$ Operation Fistula, Austin, USA

${ }^{9}$ Anaesthesia, Great Ormond Street Hospital, London, UK

\section{Correspondence to}

Dr Mark G Shrime, Harvard Medical School, Huntington Avenue, Boston, MA 02115 USA ;shrime@mail.harvard.edu

\section{ABSTRACT}

Background 81 million people face impoverishment from surgical costs every year. The majority of this impoverishment is attributable to the non-medical costs of care-for transportation, for food and for lodging. Of these, transportation is the largest, but because it is not viewed as an actual medical cost, it is frequently unaddressed. This paper examines the effect on surgical utilisation of paying for transportation.

Methods A hierarchical logistic regression was performed on 2692 patients presenting for surgical care to a nongovernmental organisation operating in the Republic of the Congo, Guinea and Madagascar. Controlling for distance from the hospital, age, gender, the need for air travel and time between appointments, the effect of payment for transportation on the surgical no-show rate was evaluated. Results After adjustment for observed confounders, paying for transportation drops the surgical no-show rate by $45 \%$ (0R $0.55 ; 95 \% \mathrm{Cl} 0.40$ to $0.77 ; p<0.001)$. Age, delay between appointments and the number of hours travelled for surgery also predict surgical no-show. For $28 \%$ of no-show patients, the cost of transportation from their homes to a nearby predetermined pick-up point remained a barrier, even when transportation from the pick-up point to the hospital was free.

Conclusion Transportation costs are a significant barrier to surgical care in low-resource settings, and paying for it halves the no-show rate. This finding highlights that decreasing demand-side barriers to surgical care cannot be limited only to the removal of user fees.

\section{INTRODUCTION}

Worldwide, five billion people lack access to safe, affordable and timely surgical care. ${ }^{1}$ Of patients who are able to get surgery every year, 81 million are forced into poverty by its costs. ${ }^{23}$ Only $40 \%$ of this impoverishment is attributable to the medical costs of surgery itself; the bulk of impoverishment comes from the direct non-medical costs of care,

\section{Key questions}

What is already known about this topic?

- 5 billion people around the world do not have access to safe, affordable and timely surgical care, and costs of care form the primary barrier.

- However, of these costs, direct medical costs make up only $40 \%$; non-medical costs, of which the cost of transportation is the largest, are a significant barrier to care.

- Because these are not routinely viewed as 'medical costs', they tend to be overlooked.

What are the new findings?

- In this paper, we examine the effect of removing the barrier of transportation cost on surgical utilisation using multivariate, hierarchical logistic regression on patients accessing free surgery through a non-governmental organisation.

- We find that, when transportation costs are paid for the surgical no-show rate drops by approximately half.

Recommendations for policy

- Traditional policy measures to increase healthcare utilisation have focused on either increasing the supply of providers or on decreasing the medical costs of care.

- We show in this study that, even when medical costs are free and providers plentiful, the cost of transportation remains a strong residual barrier that must be addressed.

such as costs for transportation, food and lodging.

Addressing the supply-side barriers to care delivery, ${ }^{4-7}$ especially those of availability and quality, has long been the focus of health system strengthening. ${ }^{8}$ This is seldom sufficient. Demand-side barriers, including the affordability of services and 
the non-medical costs of care, may be as important as supply-side barriers in deterring patients from obtaining surgical treatment. ${ }^{57}$

Many non-governmental organisations (NGOs) attempt to address demand-side barriers by offering free surgery. ${ }^{10}{ }^{11}$ Despite this, a high no-show rate has been observed. Although patient factors such as gender, distance, lack of trust, health literacy or the social environment influence utilisation, ${ }^{12}$ Massenburg et $a l^{13}$ have shown that non-medical costs, especially for transportation, remain a barrier to care, even in the setting of free care.To date, the extent to which addressing these non-medical costs of surgical care increases surgical utilisation has yet to be determined. This paper tests the hypothesis that paying for transportation to surgery will significantly decrease the surgical no-show rate in the setting of NGO-delivered free surgery.

\section{METHODS}

Mercy Ships is a global surgical NGO offering free elective surgery through its floating hospital, the Africa Mercy. Mercy Ships provides head and neck, maxillofacial, plastic and reconstructive, obstetric, orthopaedic, ophthalmological and general surgery. This study retrospectively evaluated all surgical patients admitted to the Africa Mercy between 2012 and 2016 in three low-income countries. During the study period, the Africa Mercy was docked in Guinea (2012-2013), the Republic of Congo (20132014) and Madagascar (2014-2016). Each docking, except the first year in Madagascar, was for 10 months; for logistical reasons, the first Madagascar outreach was shortened to 8 months. Diagnostics, surgeries, postoperative care, lodging and food in the perioperative period, and all equipment, supplies and medications necessary for patient care, are provided by Mercy Ships free of charge. Traditionally, the organisation has not paid for the initial costs of patient transport to attend surgery. In some cases, transportation home after patient discharge has been covered, and transportation costs are covered for patients requiring postoperative care or physiotherapy, or for other unforeseen changes in operating room schedules.

This paper examines the effect on surgical utilisation of paying for transportation to the initial surgery. During the four field services examined in this paper, some patients had this cost covered, either through a fund established by the organisation, through government funds or through collaboration with the United Nations Population Fund.

\section{Patient selection}

Prior to the arrival of the ship in any one country, a team spends 4-6months in-country, disseminating information about the surgical conditions treated and the patient selection format. After the ship's arrival, patient selection begins in the port city in which it is docked and proceeds to cities further afield.
Patient selection begins with screening by a dedicated selection team, composed of nurses and specially trained translators fluent in English, French and the local languages of each country. Patients who are deemed surgical candidates by the screening team are then brought to the ship for additional diagnostics and final screening by the surgeon who will perform their operation. Any patient deemed a surgical candidate at this final screening is given a surgery date as soon as the next day, or as far out as 2-4 weeks in the future.

Mercy Ships maintains information on all patients selected by the screening team for surgeon screening. This includes demographic information, diagnosis, proposed procedure, travel time between the screening site and the ship, the number of flights needed to get from the screening site to the ship, the number of days between initial screening and surgeon screening, and whether the patient received the scheduled surgery. Patients who do not show up for their appointment are followed up with multiple phone calls to identify the reason for no-show.

This analysis was limited to patients who lived more than 5 hours away from the ship because transportation was not provided for those who lived closer.

\section{Statistical analysis}

Missing data were handled by multiple imputation. Logistic regression was performed with no-show ( $1=$ not showing up for appointment) as the dependent variable; independent variables were whether transportation was paid for, the number of days between screening appointments, the number of hours travelled between screening and the ship, whether flights were required to get from the screening site to the ship, patient age and patient gender. Gender, flights and payment for transportation are binary; the remaining variables are continuous. Surgical specialty was also collected and was examined as a potential independent predictor. It did not meet criteria for a confounder, in that it was not associated with the exposure, and the addition of surgical specialty to the righthand side of the regression led to a worse-fitting model, with a higher Bayesian information criterion (BIC). As a result, the stable model without surgical specialty was chosen for the final results. A model including specialty is reported as a sensitivity analysis. Because data are clustered by outreach year and, within each outreach year, by screening town, a hierarchical model was constructed, reflecting this clustering. Patients in the regression were clustered within screening towns, which were themselves clustered within outreach years.

Data analysis was performed in R V.3.0 (www.r-project. org). This project received clearance from the Mercy Ships Institutional Review Board. The Institutional Review Board at the Massachusetts Eye and Ear Infirmary, where only de-identified data were received, deemed the study exempt. 
Table 1 Patient demographics

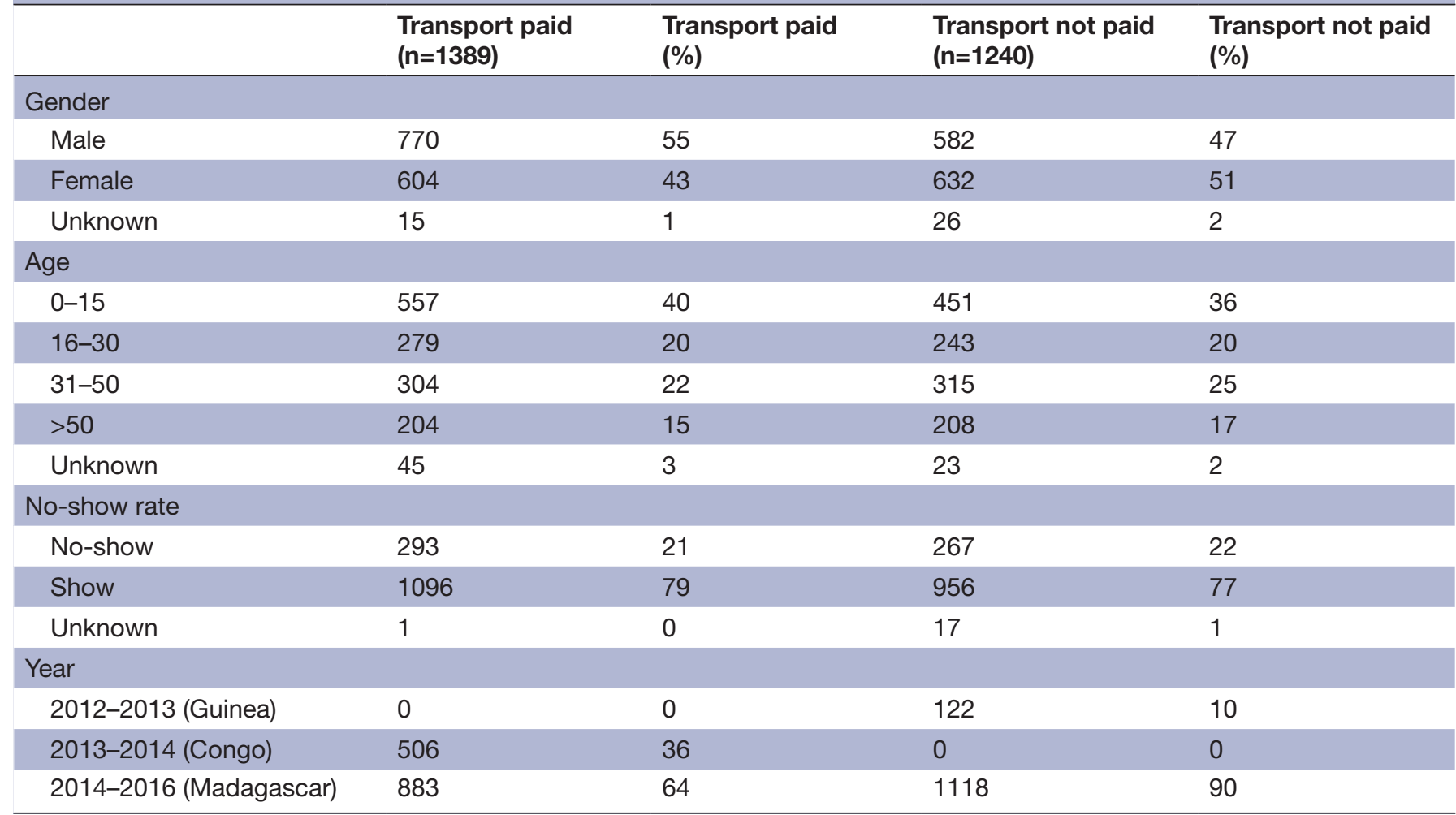

\section{RESULTS}

Between 2012 and 2016, approximately 22511 patients were screened. Only 19\% (4340) were selected as potential surgical candidates. Of these, 2629 lived further than 5 hours away and are included in the analysis. Forty-eight per cent of patients were female. The median age was 23 (range 0-96; IQR: 7-43). The median distance to the ship was 8 hours (mean 15.22, max 52, IQR: 8-20). Fiftythree per cent of patients had transportation paid for and the unadjusted no-show rate was $21 \%$ (table 1 ).

After adjustment for confounders, payment for transportation significantly decreased the no-show rate (OR $0.55 ; 95 \%$ CI 0.40 to $0.77 ; \mathrm{p}<0.001)$. Increased age was also a significant predictor of a decreased no-show rate (OR $0.89 ; 95 \%$ CI 0.80 to $1.0 ; \mathrm{p}=0.042$ ). A longer delay between screening appointments predicted an increase in the no-show rate (OR 1.54; 95\% CI 1.37 to 1.74; $\mathrm{p}<0.001)$, as did the number of hours travelled between the screening site and the ship (OR 1.41; 95\% CI 1.07 to $1.86 ; \mathrm{p}=0.014)$. Gender and the need for flights did not significantly impact the no-show rate. In addition, screening town and outreach year were not significant. The results are summarised in table 2 . In a sensitivity analysis, surgical specialty was included in the regression. Specialty itself was not significantly predictive of the no-show rate, and its inclusion slightly strengthened the effect of transportation payment on the no-show rate.

Patients who did not show for their appointment were followed up with several phone calls (this was only begun in the Madagascar field services; no data are available for the other field services). One-half of those contacted were reached; of those, $28 \%$ stated that they were unable to finance the transport to the pick-up point or health facility. Fear (15\%) and family circumstances (13\%) also played a significant role for patients whether to decide to not show up for their appointment. All the reasons identified by patients are shown in table 3. Although

Table 2 Regression results

\section{Fixed effects}

\begin{tabular}{|c|c|c|c|}
\hline & Coefficient & SE & $\mathbf{p}$ \\
\hline Intercept & -1.284 & 0.161 & $<0.001$ \\
\hline Transportation paid & -0.586 & 0.168 & $<0.001$ \\
\hline $\begin{array}{l}\text { Days between } \\
\text { appointments }\end{array}$ & 0.434 & 0.060 & $<0.001$ \\
\hline Hours travelled & 0.345 & 0.141 & 0.014 \\
\hline Any flights taken & 0.700 & 0.382 & 0.067 \\
\hline Age & -0.113 & 0.056 & 0.042 \\
\hline Female & 0.027 & 0.056 & 0.639 \\
\hline \multicolumn{4}{|l|}{ Random effects } \\
\hline & & Variance & SD \\
\hline Outreach year & & $6.2 \times 10^{-9}$ & $7.9 \times 10^{-5}$ \\
\hline $\begin{array}{l}\text { Outreach year } \times \\
\text { screening town }\end{array}$ & & 0.19 & 0.44 \\
\hline Log likelihood & -1047.2 & & \\
\hline
\end{tabular}

Note: Coefficients are log odds. ORs can be obtained by exponentiating the coefficients. 
Table 3 Reasons given by patients who did not return for their surgery

\begin{tabular}{lll}
\hline Reason & $\mathbf{n}$ & $\%$ \\
\hline $\begin{array}{l}\text { Lacked money to pay transport to } \\
\text { transportation point }\end{array}$ & 33 & 28 \\
$\begin{array}{l}\text { Surgery already done (locally/by other NGO) } \\
\text { Other (patient was ill, imprisoned, pregnant, did }\end{array}$ & 18 \\
$\begin{array}{l}\text { not follow instruction of transportation/surgery } \\
\text { date) }\end{array}$ & 19 & 16 \\
$\begin{array}{l}\text { Fear (for healthcare facility, NGO, travel, city, } \\
\text { family did not allow) }\end{array}$ & 18 & 15 \\
$\begin{array}{l}\text { Family circumstances (death, sickness in family, } \\
\text { caregiver unavailable) }\end{array}$ & 16 & 13 \\
$\begin{array}{l}\text { Work (unable to take LOA/harvest season/ } \\
\text { school/exams) }\end{array}$ & 5 & 4 \\
$\begin{array}{l}\text { Weather (rainy season/accessibility of roads) } \\
\text { Patient passed away between screening and }\end{array}$ & 3 & 3 \\
appointment & 3 & 3 \\
\hline \begin{tabular}{l} 
Total \\
\hline
\end{tabular} & 120 & 100 \\
\hline
\end{tabular}

LOA, leave of absence; NGO, non-governmental organisation.

respondents were allowed to give more than one reason for no-show, none did.

Transportation costs increased over the four outreaches, and were largest in Madagascar, which was also the largest country evaluated. Because of the distances patients had to travel to get to the facility, the use of private chartered flights for patients and the large increase of people selected further afield, the costs per patient in Madagascar averaged US\$53 for ground transportation and US $\$ 293$ for patients who required a flight.

\section{DISCUSSION}

In this paper, we show that the effect of addressing the non-medical costs of surgical care can critically influence the ability of patients in low-resource settings to access surgery. When transportation costs are paid, the surgical no-show rate drops by $45 \%$. The effect of paying for transportation on no-show was larger than all other examined covariates, including distance to the hospital.

Because transportation costs are not often considered true medical costs, their importance is often undervalued. However, current studies indicate that transport may make up as much as $30 \%$ of a patient's total out-ofpocket costs. ${ }^{1415}$ Because of an unequal rural/urban distribution of health professionals and surgical facilities, these transportation costs present an even larger obstacle to poorer surgical patients, ${ }^{16-18}$ requiring them either to forego care altogether ${ }^{19}$ or to expend significant cost to get to these facilities. ${ }^{27}$ The majority of the population in resource-poor settings does not live within 2 hours of a surgical facility; the additional out-of-pocket expenditure required for transport may therefore further impoverish already poor patients. ${ }^{20}$
In Madagascar, one of the countries involved in this analysis, $80 \%$ of the population earns less than $\$ 1.90$ a day. For this population, a standard bus ticket between two major cities can run nearly US $\$ 25 .^{21}$ Even if supplyside barriers are fully addressed with free and safe surgical care, patients may still not be able to obtain the care they need. The average per-patient cost for ground transportation in Madagascar in this study was double this price, highlighting the distance patients are required to travel for their surgery.

Results in this study are in line with prior estimates that a large portion of the 81 million impoverished by surgical costs can be attributed to non-medical costs. $^{2422} 23$ Literature addressing transport costs for other global health conditions have used vouchers, specific contracts with transport unions or community loan funds to overcome these barriers. ${ }^{5-7} 2425$ These incentives show substantial increase in utilisation of healthcare, in concordance with the findings of this paper. ${ }^{23} 2627$ Addressing the non-medical costs of care, however, requires a significant investment by governments or NGOs. Cost-effectiveness analyses of this intervention in surgery are necessary, although studies from non-surgical settings suggest that this intervention may be cost-effective. ${ }^{26} 2829$

Patients face multiple barriers in accessing necessary surgical care, including lack of trust in health facilities, distance, health literacy and delays in care. ${ }^{524} 3031$ In this study, two other factors-longer delay between appointments and number of hours travelled-were found to be barriers to attending an appointment.

Some of the key limitations of this paper include its three low-income sub-Saharan African countries in an NGO setting. As such, the findings might not generalise to other settings where transportation costs may be relatively lower compared with population income or where hospital proximity might be higher. Second, sociodemographic variables such as wealth and education may be predictors of no-show. Mercy Ships only collects these indicators for patients admitted for surgery, and as such they could not be included in an analysis of patients who were not admitted for surgery. Third, because of the specialised nature of the surgery offered by the NGO, patients are less likely to be able to access these operations at their local hospitals and health centres, necessitating further travel. This is reflected in the higher cost of transportation and longer distances travelled in this study when compared with studies that assess transportation costs for more routine health visits. ${ }^{32}{ }^{33}$ Finally, the follow-up survey may be subject to bias from cultural acceptability.

To the best of our knowledge, this is the first paper examining transportation costs specifically for surgery, and no papers have examined the costs associated with active case-finding in surgery. Costing analyses that exist examine travel to the nearest centre for more routine procedures such as caesarean section and neonatal care; they peg transportation costs for nearby care at between 
$\$ 8$ and $\$ 12 .{ }^{32} 33$ Many other costing studies explicitly exclude transport costs. ${ }^{34}$

\section{CONCLUSION}

The findings in this study indicate that surgical service providers should strongly consider subsidising or eliminating transportation costs to increase uptake of care. This is in line with existing literature in other health sectors and is likely relevant for most types of service delivery models including private, public, NGO and faithbased organisations. The study is a necessary first step to assess the impact of such demand-side costs on patients' ability and willingness to access services.

Contributors Conception or design of the work: MGS, MH, MCW. Acquisition of data: all authors except LK. Analysis or interpretation of data for the work: MGS, LK, $\mathrm{MH}$. Drafting the work: MGS, MH, SM. Revising it critically for important intellectual content: all authors. Final approval of the version to be published: all authors.

Funding MGS receives support from the GE Foundation Safe Surgery 2020 project and from the Damon Runyon Cancer Research Foundation. No specific funding was obtained for this paper.

Competing interests None declared.

Ethics approval Mercy Ships IRB and Massachusetts Eye and Ear IRB.

Provenance and peer review Not commissioned; externally peer reviewed.

Data sharing statement Data sharing requests are subject to approval by the Mercy Ships Institutional Review Board.

Open Access This is an Open Access article distributed in accordance with the Creative Commons Attribution Non Commercial (CC BY-NC 4.0) license, which permits others to distribute, remix, adapt, build upon this work non-commercially, and license their derivative works on different terms, provided the original work is properly cited and the use is non-commercial. See: http://creativecommons.org/ licenses/by-nc/4.0/

C Article author(s) (or their employer(s) unless otherwise stated in the text of the article) 2017. All rights reserved. No commercial use is permitted unless otherwise expressly granted.

\section{REFERENCES}

1. Meara JG, Greenberg SL. The lancet commission on global surgery global surgery 2030: evidence and solutions for achieving health, welfare and economic development. Surgery 2015;157:834- http://a c.els-cdn.com/S0039606015001488/1-s2.0-S0039606015001488-m ain.pdf?_tid=d4a9f8ce-24de-11e7-8d9f-00000aacb360\&acdnat=149 2592693_e233f6f618331b6dfa5ca2556df31e3f.

2. Shrime MG, Dare AJ, Alkire BC, et al. Catastrophic expenditure to pay for surgery worldwide: a modelling study. Lancet Glob Health 2015;3 Suppl 2:S38-S44.

3. Shrime MG, Dare A, Alkire BC, et al. A global country-level comparison of the financial burden of surgery. Br J Surg 2016;103:1453-61.

4. Peters DH, Garg A, Bloom G, et al. Poverty and access to health care in developing countries. Ann N Y Acad Sci 2008;1136:161-71.

5. O'Donnell O. Access to health care in developing countries: breaking down demand side barriers. Cad Saude Publica 2007;23:2820-34.

6. Standing H. Understanding the "demand side" in service delivery. Vol 44. Sussex, UK, 2004.

7. Ensor T, Cooper S. Overcoming barriers to health service access: influencing the demand side. Health Policy Plan 2004;19:69-79.

8. WHO. Monitoring the building blocks of health systems. A handbook of indicators and their measurement strategies. Who 2010:1-92.

9. Development $\mathrm{H}$, Packard T. What is a health system? Heal Dev World Bank Strateg HNP Results 2007:1-4.

10. Shrime MG, Sleemi A, Ravilla TD. Charitable platforms in global surgery: a systematic review of their effectiveness, costeffectiveness, sustainability, and role training. World J Surg 2015;39:10-20.
11. Ng-Kamstra JS, Riesel JN, Arya S, et al. Surgical non-governmental organizations: global surgery's unknown nonprofit sector. World $J$ Surg 2016;40:1823-41.

12. Lin BM, White $M$, Glover $A$, et al. Barriers to surgical care and health outcomes: a prospective study on the relation between wealth, sex, and postoperative complications in the republic of congo. World $\mathrm{J}$ Surg 2017;41:1-10.

13. Massenburg BB, Jenny HE, Saluja S, et al. Barriers to cleft lip and palate repair around the world. $J$ Craniofac Surg 2016;27:1741-5 http://ovidsp.uk.ovid.com/sp-3.25.0a/.

14. Cambanis A, Yassin MA, Ramsay A, et al. Rural poverty and delayed presentation to tuberculosis services in Ethiopia. Trop Med Int Health 2005; 10:330-5

15. Terra de Souza AC, Peterson KE, Andrade FM, et al. Circumstances of post-neonatal deaths in Ceara, Northeast Brazil: mothers' health care-seeking behaviors during their infants' fatal illness. Soc Sci Med 2000;51:1675-93.

16. Lehmann U, Dieleman M, Martineau T. Staffing remote rural areas in middle- and low-income countries: a literature review of attraction and retention. BMC Health Serv Res 2008;8:19.

17. Alkire BC, Raykar NP, Shrime MG, et al. Global access to surgical care: a modelling study. Lancet Glob Health 2015;3:e316-e323.

18. Campbell J, Dussault G, Buchan J, et al. A universal truth: No health without a workforce. Forum Rep Third Glob Forum Hum Resour Heal Glob Heal Work Alliance World Heal Organ.

19. Meremikwu MM, Ehiri JE, Nkanga DG, et al. Socioeconomic constraints to effective management of Burkitt's lymphoma in southeastern Nigeria. Trop Med Int Health 2005;10:92-8.

20. Raykar NP, Bowder AN, Liu C, et al. Geospatial mapping to estimate timely access to surgical care in nine low-income and middleincome countries. Lancet 2015;385:S16.

21. Mensah M. The response to AIDS in madagascar, 2007:1-49. http:// www.unaids.org.

22. Grimes CE, Henry JA, Maraka J, et al. Cost-effectiveness of surgery in low- and middle-income countries: a systematic review. World $J$ Surg 2014;38:252-63.

23. Bieberly J, Ali J. Treatment adherence of the latently infected tuberculosis population (post-Katrina) at Wetmore TB Clinic, New Orleans, USA. Int J Tuberc Lung Dis 2008:12:1134-8.

24. Price JA, Soares AI, Asante AD, et al. "I go I die, I stay I die, better to stay and die in my house": understanding the barriers to accessing health care in Timor-Leste. BMC Health Serv Res 2016;16:535.

25. Jacobs B, Ir P, Bigdeli M, et al. Addressing access barriers to health services: an analytical framework for selecting appropriate interventions in low-income Asian countries. Health Policy Plan 2012;27:288-300.

26. Alam N, Chowdhury ME, Kouanda S, et al. The role of transportation to access maternal care services for women in rural Bangladesh and Burkina Faso: a mixed methods study. Int J Gynaecol Obstet 2016;135:S45-S50.

27. Samai $O$, Sengeh $P$. Facilitating emergency obstetric care through transportation and communication, Bo, Sierra Leone. The Bo PMM Team. Int J Gynaecol Obstet 1997;59:S157-S164.

28. Sacks E, Vail D, Austin-Evelyn K, et al. Factors influencing modes of transport and travel time for obstetric care: a mixed methods study in Zambia and Uganda. Health Policy Plan 2016;31:293-301.

29. Wei X, Zou G, Yin J, et al. Providing financial incentives to ruralto-urban tuberculosis migrants in Shanghai: an intervention study. Infect Dis Poverty 2012;1:9-8 http://download.springer.com/static/ pdf/205/art\%253A10.1186\%252F2049-9957-1-9.pdf originUrl= http\%3A\%2F\%2Fidpjournal.biomedcentral.com\%2Farticle\% 2F10.1186\%2F2049-9957-1-9\&token2=exp=1492637917 acl=\% 2Fstatic\%2Fpdf\%2F205\%2Fart\%25253A10.1186\%25252F20499957-1.

30. Dare AJ, Ng-Kamstra JS, Patra J, et al. Deaths from acute abdominal conditions and geographical access to surgical care in india: a nationally representative spatial analysis. Lancet Glob Health 2015;3:e646-e653.

31. Adriaan J, Van Loenhout F, Delbiso TD, et al. Barriers to surgical care in Nepal.

32. Honda A, Randaoharison PG, Matsui M. Affordability of emergency obstetric and neonatal care at public hospitals in Madagascar. Reprod Health Matters 2011:19:10-20.

33. Haddad S, Ridde V, Yacoubou I, et al. An evaluation of the outcomes of mutual health organizations in Benin. PLoS One 2012;7:e47136.

34. Storeng KT, Baggaley RF, Ganaba R, et al. Paying the price: the cost and consequences of emergency obstetric care in Burkina Faso. Soc Sci Med 2008;66:545-57. 